\title{
Abrasive Wear and Abrasion Testing of PA 6 and PEEK Composites in Small-Scale Model System
}

\section{László Zsidai, László Kátai}

Szent István University, Faculty of Mechanical Engineering, Institute for Mechanical Engineering Technology

Páter K. u. 1, H-2100 Gödöllö, Hungary

email: zsidai.laszlo@gek.szie.hu; katai.laszlo@gek.szie.hu

Abstract: Abrasion wear is one of the most common failure mechanisms of moving machine elements. Because of their mechanical and tribological ability, engineering polymer composites can be chosen to replace metal parts in certain applications (e.g. bearings). Increasingly newer polymer composites are appearing and data on their tribological behaviours are incomplete, it is not so easy to choose from this wide wide selection of choices (mechanical properties, price, etc.). In the present study two groups of polymer composites (PA 6 and PEEK with different mechanical properties and prices) are experimentally investigated by a unique small-scale abrasion tribotesting. The main objectives of our study were to compare the tribological properties of composites and to investigate the effect of different additives and mechanical properties. The tests were prepared using the pin on plane (band) model system and tested on different loads (11.5 N and $23 \mathrm{~N}$ ), where the abrasion mating surface was emery cloth. We found among other things that the fillings have a favourable effect on PA opposite to PEEK. The short carbon fibres proved better for improving wear resistance as compared to short glass fibres. Our present work is connected to a research project, which aims to map the tribological features of different polymer composites.

Keywords: abrasion; PA 6; PEEK; friction; tribology

\section{Introduction}

Abrasion is the most common type of wear in industrial practice. It occurs when the micro-roughness of the harder counter body ploughs through the softness of the counter surface. Material is removed by micro cutting or micro cracking, and wear results by sharp and rigid particles or peaks of roughness. Wear gaps are created by the scratches of the surface. The particles that leave the gap are called the wear. Abrasive wear can occur in all places, where rigid particles can go between the sliding surfaces (e.g. in dusty work zone), where the surface 
roughness is high, or the hardness of the sliding elements is very different, or if the machine works with abrasive material. Briscoe and Sinha [3] mentioned that cohesive wear results from surface and subsurface deformations, caused by the harder asperities of the counterface. Abrasion and fatigue wear processes are termed, 'cohesive wear'.

We can use machine elements (e.g. efficient seals) and optimal surface parameters to the reduce effects of abrasion wear, but unfortunately these are not always possible (e.g. in heavy dusty places, such as in agriculture, and in the mining industry). We may use tough or elastic materials or coatings with high strength to solve in these situations. The polymers and polymer composites can be chosen as sliding materials (because of their good deformation ability) in abrasive applications during the machine construction also as a counter measure. Regardless of the metals, where the cutting is the most important abrasion process, with polymers tearing-sheller effects are the most dominant. Polymer composites can also improve the tribological properties of the base polymers in an abrasion friction system. Several publications deal with the base mechanism of the abrasion wear [5, 6, 11] and its role in the machine industry applications [21] and the abrasion features of the polymers also [7, 9, 12, 24].

The abrasion friction test instruments are developed parallel to the former ones. Several standards (ASTM, DIN and ISO) deal with the abrasion tests of the polymers: ASTM D1242 is a standard test method to see the resistance of plastic materials to abrasion [8], ASTMD 3389 is for coated fabrics (rotary platform, double-head abrader), ASTM G 75 to determine the slurry abrasivity (miller number) and slurry abrasion response of materials (SAR Number) and ASTMG 132-96 for pin abrasion testing. DIN 52347 is for testing of glass and plastics and DIN 53516 is for testing of rubber and elastomers. ISO 4649 is for rubber, vulcanized or thermoplastic using a rotating cylindrical drum device and ISO 5470-1 for rubber- or plastics-coated fabrics and ISO 23794 is for rubber, vulcanized or thermoplastic [30]. These rigs are available in the technical market as a professional product [27]. Most of the previous model systems worked in sand slurry, liquid (cavitation ASTM G32-134), or gas (ASTM G76). Some examinations make it possible to do tests with reciprocating motion against plane or abrasion wheel in counterformal contact.

One of the capital novelties and key to our work is the unique model system, which developed the abrasion tribotest rig. The equipment makes it possible to obtain linear abrasion friction measurements of the different polymers on emery cloth using a pin-on-plate (band) test apparatus with one-way continuous motion in conformal contact (modeling most applications well, e.g. sliding bearings, Vbelt, gears). No external lubricants were added to the tribological system.

The selected polymers were investigated with respect to friction and wear characteristics. The selection was based on a base polymer and different composites as applied by manufacturers and users. We selected two polymer 
groups with special characteristics and significant differences between their mechanical properties and prices. Among many types of polyamides (PA), four PA were tested (PA 6 E reference, PA 6MO, PA 6G ELS, PA 6GLIDE). The relatively expensive PEEK (Poly-Ether-Ether-Ketone) was tested for base and composites PEEK PVX and PEEK GF30 that are widely used nowadays (e.g. medical implants, industrial sealings) were included in the experiments.

Many results can be found in the literature, that are connected to the mechanical and abrasion behaviours of the tested polymer groups. Polyamide 6 is a well known polymer [20, 22, 23, 37], therefore we will give a short overview of the tribological properties of PEEK composites mainly.

Several authors $[2,30]$ wrote that the friction coefficient of PEEK decreases with increasing temperature, it passes through an optimum point (around the glasstransition temperature at $143{ }^{\circ} \mathrm{C}$ ) and then increases slightly. Shao et al. [36] and Wang et al. [29] found that micro and nanosized abrasive $\left(\mathrm{SiO}_{2}\right)$ fillers in PEEK provided lower wear rates and lower coefficients of friction than the unfilled polymer, and he reported also [28], that nanoparticles of $\mathrm{ZrO}_{2}$ as the filler were effective in reducing the wear rate of PEEK.

The literature [25, 26, 32] shows a wide variety of different fillers available such as solid lubricants for reducing friction, reinforcing fibers for high mechanical strength or hard particles for abrasion resistance. In the literature we can see that the addition of carbon fibre (CF) to polymers resulted in increased hardness, tensile and flexural strength [13] and increased glass transition temperature [14]. Unlubricated sliding wear behaviour of short glass fibre (GF) and carbon fibre (CF) reinforced PEEK have been investigated by Voss et al. [10] and Friedrich et al. $[18,19]$. They concluded that short carbon fibres proved better for improving wear resistance as compared to short glass fibres, but this trend can change under certain "pv limit" (contact pressure multiplicity sliding velocity) conditions.

To create a continuous transfer layer, solid lubricants, like graphite and PTFE are commonly used $[1,15]$. More investigations describe that the 10-25 wt $\%$ of PTFE give an optimal wear resistance and minimum frictional coefficients for the PEEK composites PTFE [4, 31, 38, 39]. However, other studies point at important effects of the filling manner of PTFE, where the wear rates obtained from the inclusion of expanded PTFE filaments were better than conventional powder filled PTFEPEEK composites. [16]

Friedrich and Alois K. Schlarb [17] refer to the tribological differences between PEEK and PA 6. They emphasize that for the low wear rate of PEEK makes a relative higher friction coefficient, but in case of the PA 6 both properties are low. For PEEK, the role of nanoparticles is to increase the load-bearing capacity of the material, and thus the actual contact area is reduced leading to lower frictional stress for the nanocomposite. 
The main objectives of our investigations are:

- comparison of friction and wear behaviour of different PA and PEEK composites in connection with mechanical properties,

- presentation of a special abrasion test system, with one way motion and conformal contact,

- determination of optimal operational conditions of the selected polymers.

This article aims to be helpful in the selection of a proper polymer for a given operational condition.

\section{Experimental Procedure}

\subsection{Apparatus}

The experimental set-up as pictured in Fig. 1, is a unique building abrasion tribotester.

The detailed figure shows that continuous sliding friction is created by a polymer cylinder (1), which moves against a lower emery cloth (2) in conformal contact. The polymer specimen is fixed to the fixture (3) by nuts, preventing it from rolling during the test, and thus simple sliding is guaranteed. The continuous one-way motion of the emery cloth is provided by a controlled variable speed motor (4) through a twin roll power transmission (5) to produce the sliding motion. The abrasive emery cloth is tightened to a pair of rolling drums, and the friction contact is placed between these in the middle position. A metal plate is placed under the moving slide, therefore the contact abrasive surface will be a plane.

The machine is equipped with a manual loading system (6), which consists of a plate (7) and a vertical column (8), mechanically pulled down by loading weights (9). A head (load-cell) with strain gauges (10) is used to measure the friction force. The normal displacement of the cylindrical specimen towards the steel plate, as a result of the wear, is measured by a linear gauge (11). The vertical column and the linear gauge with supporting spindles are built in the console head (12).

The more detailed close-up of the equipment (upper-center) shows the manual load system and the special form of the measure head. 

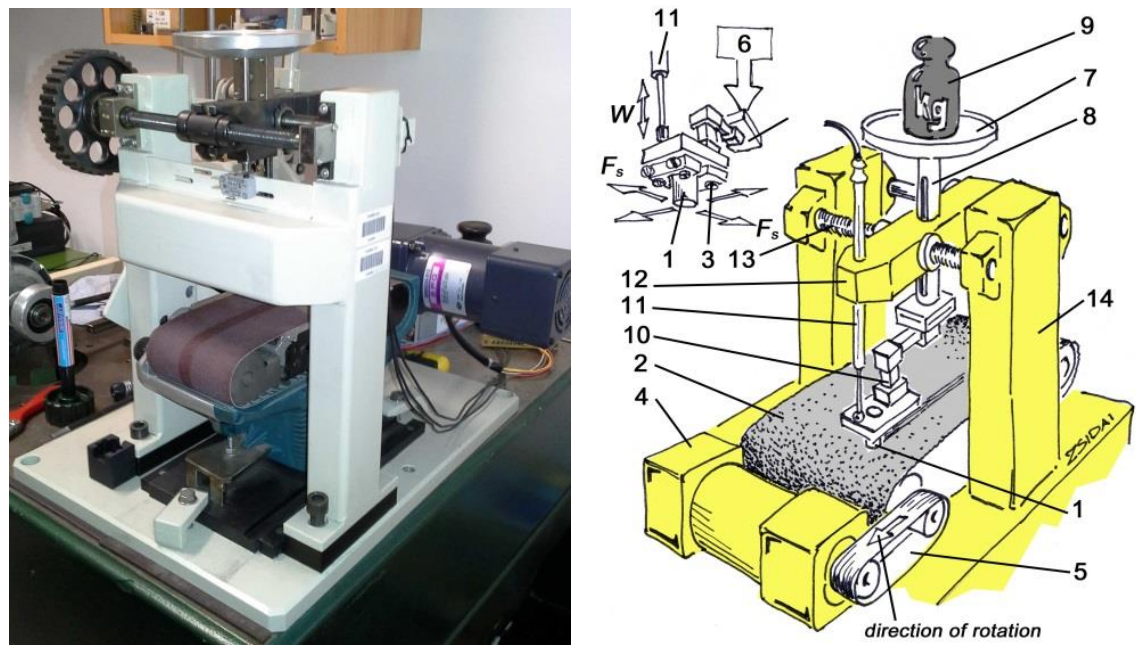

Figure 1

Abrasion testing equipment (photo and schematic view):

(1) polymer specimen; (2) emery cloth; (3) nuts and clamp; (4) electrical motor; (5) twin roll driving system; (6) manual loading system; (7) plate; (8) vertical column ; (9) weights; (10) load-cell; (11) linear gauge (for vertical displacement as a result of wear); (12) console head unit; (13) spindle for cross movement (it wasn't used for present tests)

\subsection{Test Conditions}

All experiments were performed in ambient temperate and humidity $\left(25^{\circ} \mathrm{C}\right.$ and $50 \% \mathrm{RH})$. The various conditions of the small-scale tests performed are gathered in Table 1.

Table 1

Parameters of tests

\begin{tabular}{|l|c|}
\hline Parameters & Values \\
\hline Type of the emery cloth & DEER XA167AA-100 \\
\hline Running time, $\mathrm{t}[\mathrm{s}]$ & 240 \\
\hline Normal load, $\mathrm{F}_{\mathrm{N}}[\mathrm{N}]$ & 11.5 and 23 \\
\hline Length of emery cloth $[\mathrm{mm}]$ & 610 \\
\hline Velocity, $\mathrm{v}[\mathrm{m} / \mathrm{s}]$ & 0.05 \\
\hline Total sliding distance $[\mathrm{m}]$ & 12 \\
\hline Humidity, RH $[\%]$ & 50 \\
\hline Ambient temperature, $\mathrm{T}\left[{ }^{\circ} \mathrm{C}\right]$ & 25 \\
\hline
\end{tabular}


Tests were conducted with normal load: $11.5 \mathrm{~N}$ and $23 \mathrm{~N}$. The running time (240 s) of the tests were chosen in order to observe the wear value and the first (running in stage) period of the friction. For each test, the surface roughness of the emery cloths were determined by the type of abrasive DEER XA 167 AA-100. The tribological data described below result from an average of three runs with identical experimental parameters.

\section{Materials and preparation of test specimens}

The selection of the tested seven polymers and composites were made by cutting an $8 \mathrm{~mm}$ diameter and a $10-15 \mathrm{~mm}$ length. The materials can be divided into two main composites groups. The experiments included one with a PA6, and the other with a PEEK base matrix.

\section{Material of the mating plate}

The counter plates are abrasive industrial emery cloth (type: DEER XA 167 AA100 ), and it was chosen as a typical abrasion effect for the industry. The grain type of the grinder is Aluminium-Oxide and the bonding material is resin. [33]

\section{Materials of the polymer cylinders}

Table 2 gives an overview of the properties of the tested engineering plastics. Among these properties the E-modulus can be used to characterize the adhesion friction component, since it is correlated with the chain flexibility. The deformation ability is determined by tensile stress and strain, as their product is equivalent to the work of rupture and the material's toughness.

Table 2

Mechanical and physical properties of the tested polymers [34, 35]

\begin{tabular}{|l|c|c|c|}
\hline Material code & colour & $\begin{array}{c}\text { density } \\
\text { [g/cm }^{\mathbf{3}} \text { ] }\end{array}$ & $\begin{array}{c}\text { Tensile strength at } \\
\text { yield/ Modulus of } \\
\text { Elasticity [MPa] }^{(\mathbf{1})}\end{array}$ \\
\hline PA 6E natural & black & 1.14 & $80 / 3200$ \\
\hline PA 6G ELS & black & 1.15 & $90 / 3400$ \\
\hline PA 6MO & black & 1.16 & $80 / 3400$ \\
\hline PA 6 Glide & green & 1.13 & $76 / 3200$ \\
\hline PEEK natural & beige & 1.31 & $116 / 4200$ \\
\hline PEEK PVX & black & 1.44 & $84 / 5500$ \\
\hline PEEK GF 30 & yellow & 1.53 & $105 / 6400$ \\
\hline
\end{tabular}

(1) Values referring to material in equilibrium with the standard atmosphere $23^{\circ} \mathrm{C} / 50 \% \mathrm{RH}$

The list shows a short description of the tested polymers below. [34, 35]:

- The extruded type polyamide PA 6E were used as a reference material in the investigations. This polyamide has been a strategic engineering plastic for many years all over the world, thanks to the favourable performance/price 
ratio. It offers a favourable combination of strength, toughness, mechanical damping ability and wear resistance. The product can be regarded as a polyamide type "for general use".

- The PA 6G ELS is the conductive version of magnesium catalysed cast polyamide 6 .

- In comparison the PA 6MO (PA 6E+MoS 2 ) with the PA 6E material, it has a higher degree of strength and rigidity due to the molybdenum disulphide $\left(\mathrm{MoS}_{2}\right)$ content. Its heat and wear resistance is better, but its toughness and mechanical damping ability is worse. It can be readily machined with automatic cutting machines.

- PA 6 Glide is a hard semi-crystalline cast thermoplastic with a lubricant addition. It has good sliding properties, wear resistance, better tensile strength and machinability than PA 6E. Typical applications are (e.g. gears, rollers, cable rollers, universal material) wherever there are no special requirements.

- Natural, unfilled PEEK (polyetheretherketone) is a semi-crystalline advanced material that exhibits a unique combination of high mechanical properties, temperature resistance, and an excellent chemical resistance. The main properties are a high service temperature (permanently around $250{ }^{\circ} \mathrm{C}$, briefly to $310^{\circ} \mathrm{C}$ can be used), high mechanical strength, stiffness, excellent chemical, hydrolysis, wear resistance and good dimensional stability.

- PEEK PVX is a real bearing grade. It is filled with carbon fibres (CF), PTFE and graphite.

- PEEK GF30 composite contains 30\% glass fibre (GF) reinforced for greater dimensional stability and higher strength properties.

The original forms, colours and dimensions of the small-scale specimens are included in Fig. 2. The polymer cylinder has a diameter of $8 \mathrm{~mm}$ and length of 10$15 \mathrm{~mm}$.

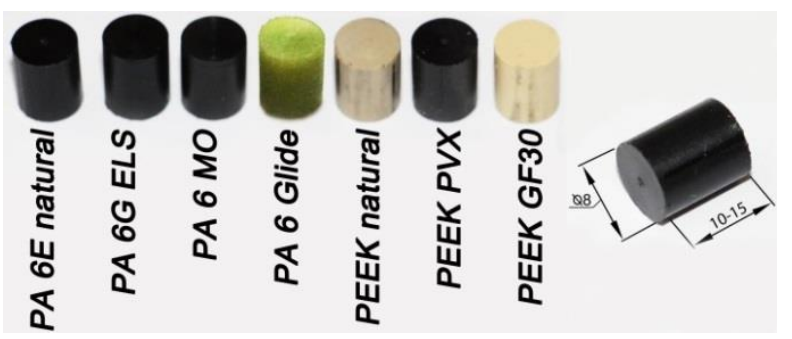

Figure 2

Original form and dimensions of the tested polymers and composites

The cylindrical specimens are in conformal connection with the abrasive (emery cloth). The components of composites are homogenously spread in the bulk of polymers. 


\section{Test Results And Discussion}

\subsection{General}

Friction and wear results of the small-scale abrasion tests for both load categories $(11.5 \mathrm{~N}$ and $23 \mathrm{~N})$ are described in this section. For the correct interpretation of the graphs and tables mentioned below, the following annotations are emphasised:

Column charts: The dynamic and the maximum friction coefficients are represented in Figs. 3 and 5. For each material, the first column refers to maximum value of the friction and the second one refers to the dynamic friction coefficient. The white arrow marks the instable tendency (slowly growing, slowly decreasing). The wear is represented in Fig. 7. For each material the first column refers to the wear value of the lower load $(11.5 \mathrm{~N})$ and the second one refers to the wear of the higher load $(23 \mathrm{~N})$ tests. All values are averaged from three test runs with identical parameters.

Dynamic friction characteristics: The real friction curve as a function of sliding distance is shown in Fig. 4 and Fig. 6 for a given load and emery cloths. For example, for some polymer, only one typical curve of the three runs, is shown to reveal the differences in friction behaviour during the running-in stage and steady state regime. It has to be mentioned that the periodically repetitive more or less similar instabilities can be seen on the curves at the joint of the emery cloth bands.

\subsection{Lower Load (11.5 N) Test Category}

Figs. 3-4 show the dynamic and maximum friction coefficient of polymers tested under the lower $11.5 \mathrm{~N}$ loads.

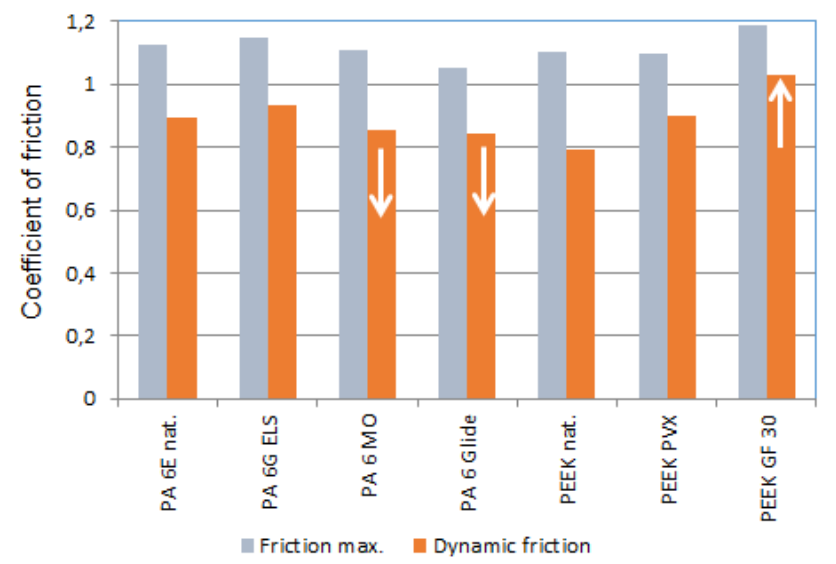

Figure 3

Dynamic friction coefficient (dark) and its maximum value (light) at lower $11.5 \mathrm{~N}$ load 


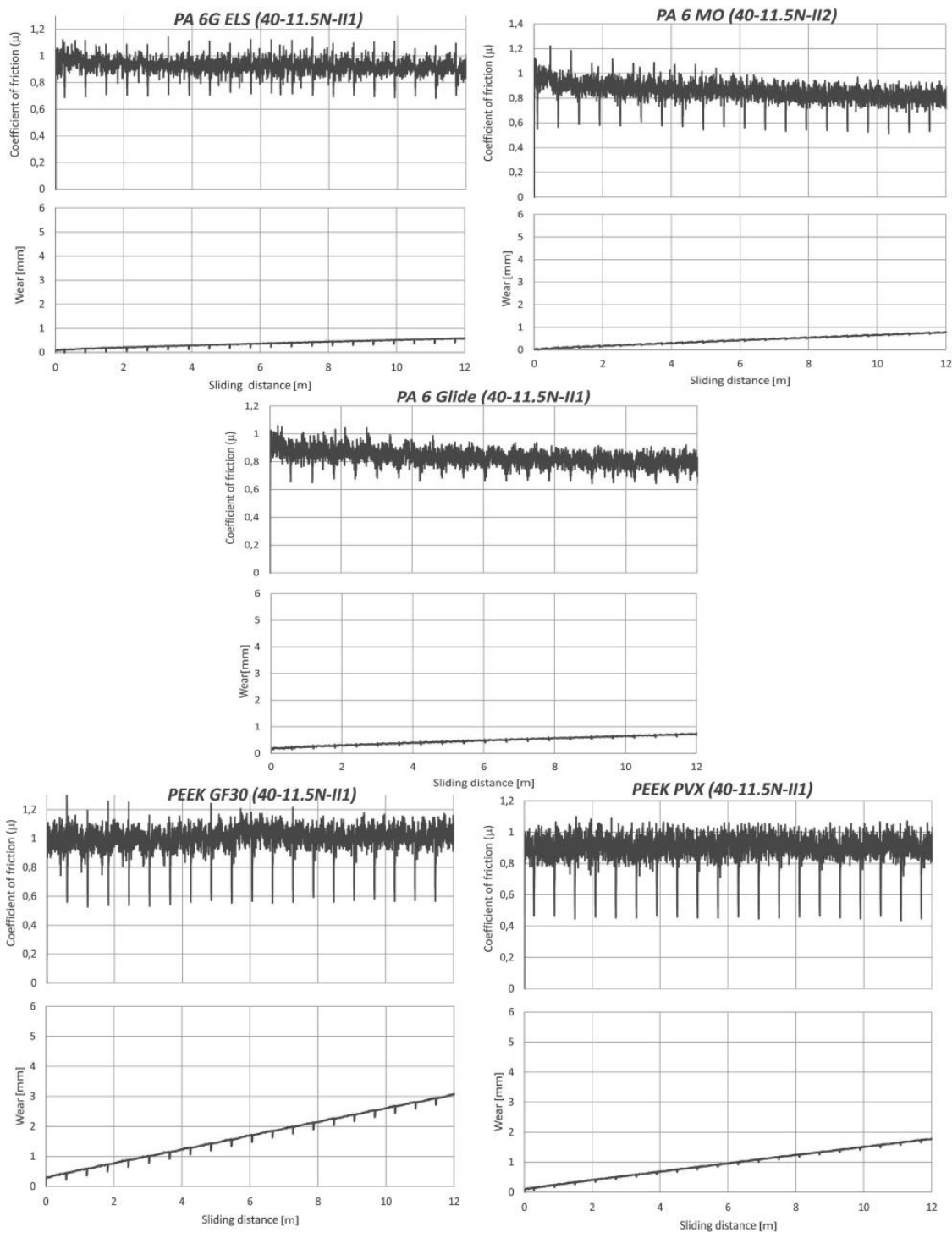

Figure 4

Dynamic friction and wear characteristics of tested composites against emery clothes at $11.5 \mathrm{~N}$ load

- From the view point of the dynamic friction, PEEK natural is most favourable and seems to have the lowest values over the total sliding time. However, the highest instability in the friction, which is shown by the maximum value of it's. PEEK PVX has a similar value of maximum friction but a higher dynamic value than natural PEEK. The highest frictions (maximum and dynamic) are represented by PEEK GF 30 on abrasive surfaces, this value is not constant but shows a slight increase during the running-time (Fig. 4). 
- The friction behaviours are similar for PA 6E and PA 6G ELS, and they are very stable during the test (Fig. 4). Figure 4 shows the friction and wear curves of PA $6 \mathrm{MO}$ and PA 6 Glide, these values are not constant but show a slight decrease during the running-time.

- The PA composites (mainly PA 6 Glide and PA MO) show a lower friction in opposite the PEEK composites. PA 6 Mo (Fig. 4) shows better sliding properties than PA 6E and PA 6G ELS. This behaviour is interesting because it is opposite to the effect of molybdenum addition (being tougher). The highest friction is presented by PA 6 ELS among all tested PA composites in lower load category.

\subsection{Higher Load (23 N) Test Category}

With the application of higher $(23 \mathrm{~N})$ load, the dynamic friction coefficients and maximum friction of the polymers are represented in Figs. 5-6.

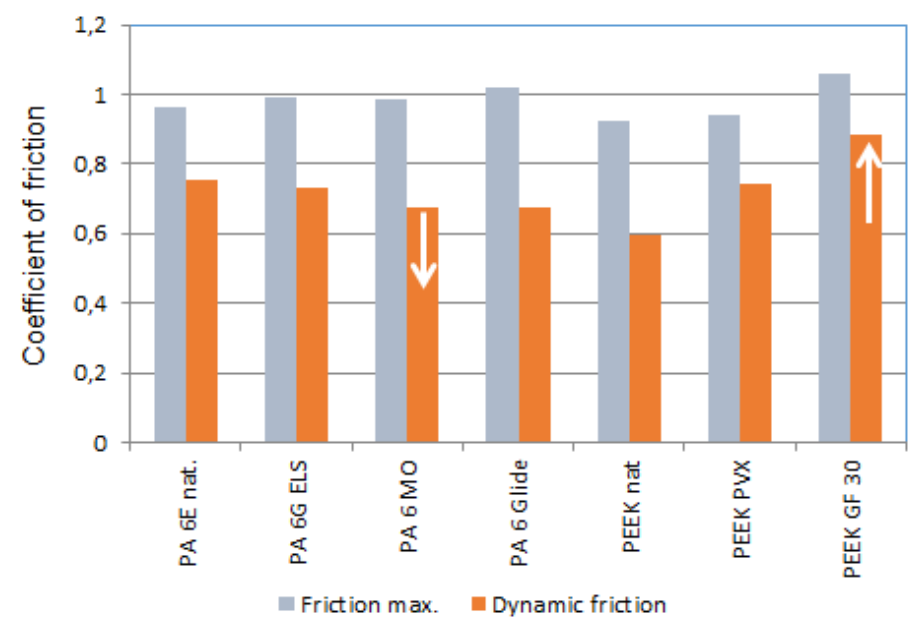

Figure 5

Dynamic friction coefficient (dark) and its maximum value (light) at higher $23 \mathrm{~N}$ load 

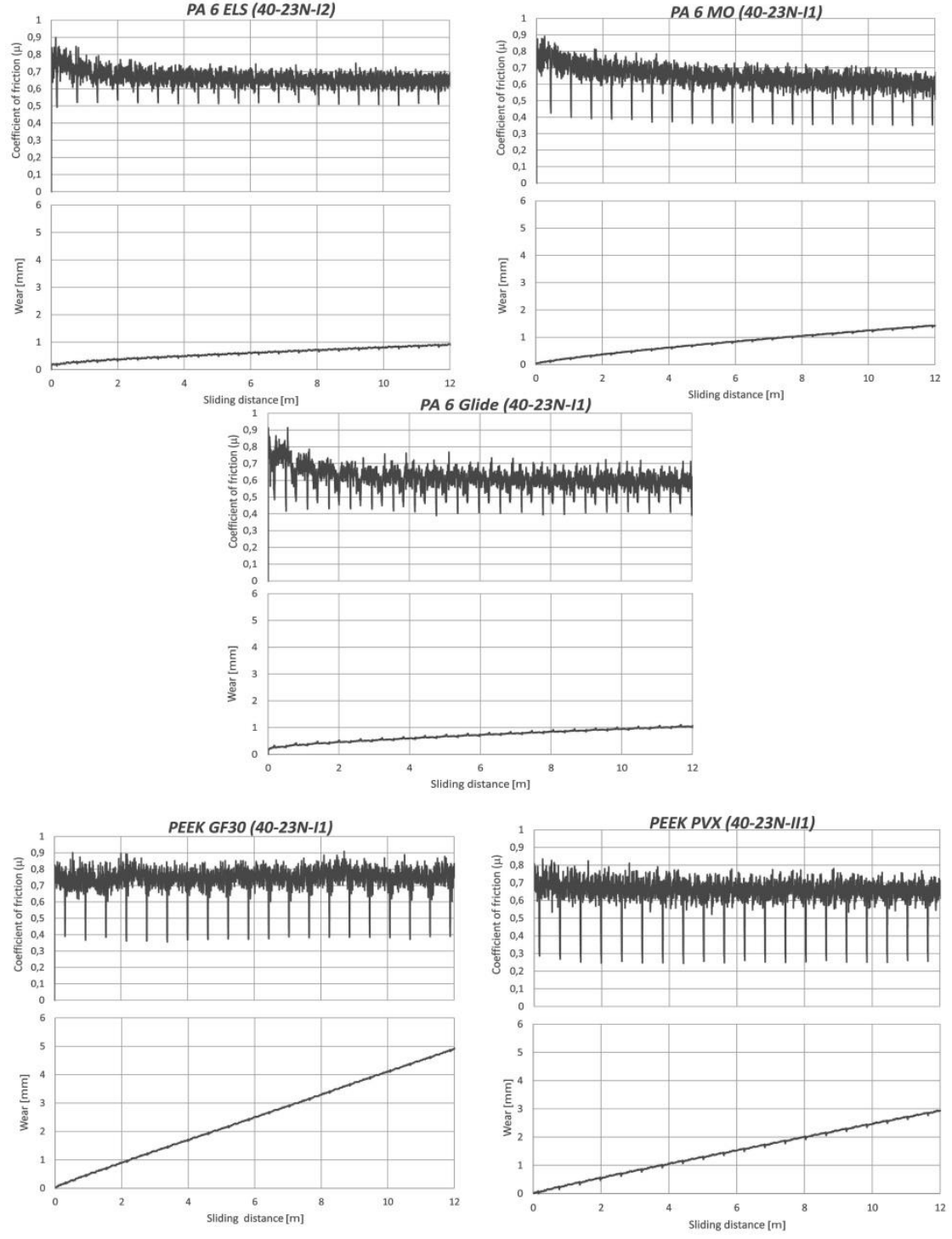

Figure 6

Dynamic friction and wear characteristics of tested composites against emery clothes at $23 \mathrm{~N}$ load

Comparing Fig. 3 and Fig. 5, it appears that globally under high loads the friction coefficient is lowered. We can see a similar difference and range among the friction behaviours of tested polymers at lower load categories.

- In accordance with the previous, the PEEK natural has the lowest friction coefficient under higher load (similar to lower load). 
- In contrast to the results of the lower load category another range occurs between PA 6G ELS and PA 6E natural, in favour of PA 6G ELS.

- The friction of PA 6 Glide is more stable than when it was at a lower load. PA 6 Mo (Fig. 6) has similar favourable sliding properties as PA 6 Glide but shows a slight decrease during the running-time.

- PEEK GF30 shows the worst results in connection to friction coefficients and wear among the tested polymers.

\subsection{Comparison of the Wear of Different Load Categories}

It is clear that the effect of adhesion decreases with increasing load and increasing surface roughness. In our case the abrasion now becomes more important. The abrasion wear results of the tested polymers are shown in the Fig. 7 for both load categories. We can measure both the wear and deformation together, however because of the small loads- this is negligible in the present study.

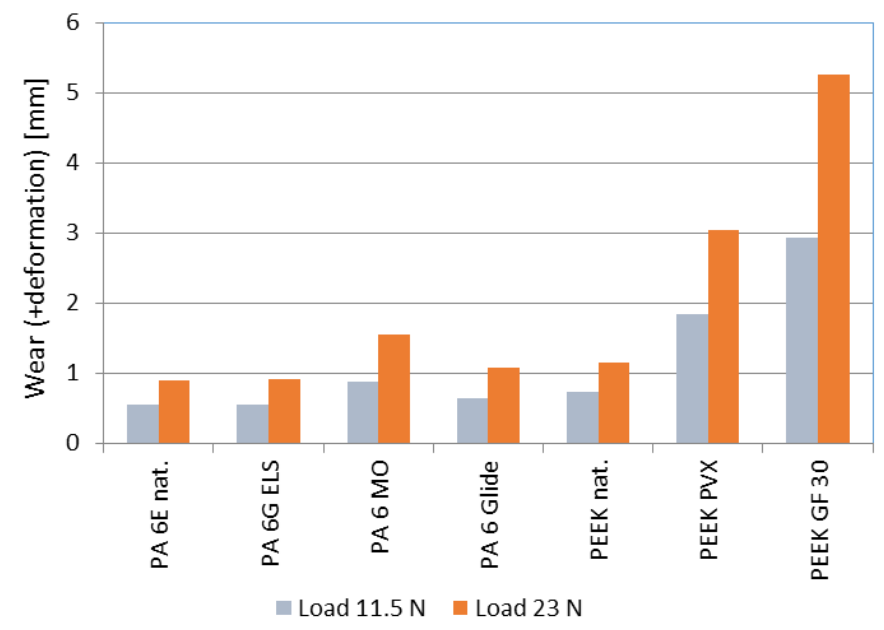

Figure 7

Wear values for different materials in $11.5 \mathrm{~N}$ and $23 \mathrm{~N}$ load categories

We can compare these results. It can be observed from the figure that the higher load increases proportionally ( 1.6 times) in the wear of most of tested polymers.

- But in cases two of PA 6MO and PEEK GF 30 we can see bigger differences between the wear results. The wear is measured at a higher load, 1.77 times more than measured at a lower load. These polymers are a little bit more sensitive against the different loads. 
- PA 6E natural has the lowest wear results close to PA 6G ELS. It can be observed from the wear result of these polymers, that they have increased deformation ability, due to the lower tensile stress and lower strain at break.

- The highest wear values are shown by PEEK PVX and mainly PEEK GF30, they are said to be more rigid because of their higher modulus of elasticity. So in our abrasion case the rigid behaviours can cause a higher value of wear.

- The polyamides show a better wear result among tested polymers in both categories, according to the low elasticity modulus of this polymer. The flexibility of the polymer chains is enhanced for soft materials (reflected by a low elasticity modulus), a better more effective transfer can occur.

Fig. 8 shows polymer films of all tested polymers (at first the PEEK, then PA 6) in the wear track, which are studied by a digital camera after the test. The forms and filling in the abrasive surface, show us the results of the wear behaviour of tested polymers.

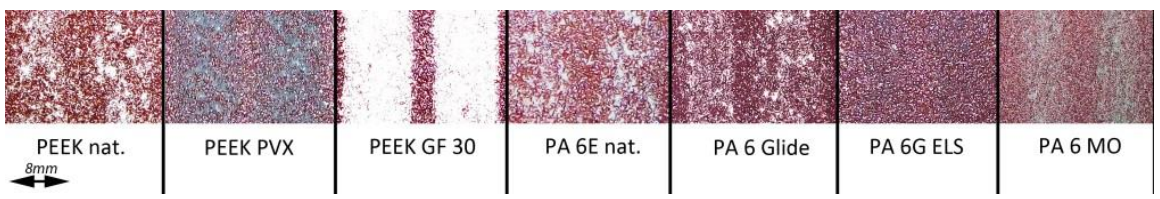

Figure 8

Different wear tracks on the emery cloth at $11.5 \mathrm{~N}$ load

- In the case of PEEK, natural non-continuous plastic layers cover the surface with several large and bitty wear particles.

- For both PEEK composites (PVX and GF30), the polymer films are thick and a more or less homogenous track (mainly GF30) is observed.

- The smallest and thinnest transfer layer is shown by polyamides; this great correlation makes them preferable for their wear properties.

According to generally accepted friction models, two mechanisms contribute to the friction force between a thermoplastic and steel: adhesion in the contact zone and deformation of the polymer $[9,11]$. Their relative contribution depends on several conditions like load level, as well as, on the chemical, mechanical and geometrical properties. However, the surface roughness is the most important factor among them. The deformation ability of the polymers, basically determines the abrasion resistance of the tested polymers. Therefore, we have to see the mechanical properties of the polymers. The tensile strength at yield and modulus of elasticity were shown in Table 2, and the hardness (type: Shore D for rigid polymer tested by Zorn Stendal 8036 hardness tester) due to wear are illustrate in Fig. 9. 


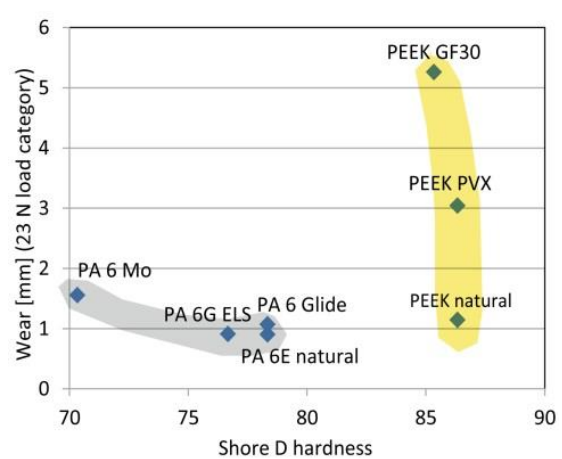

a)

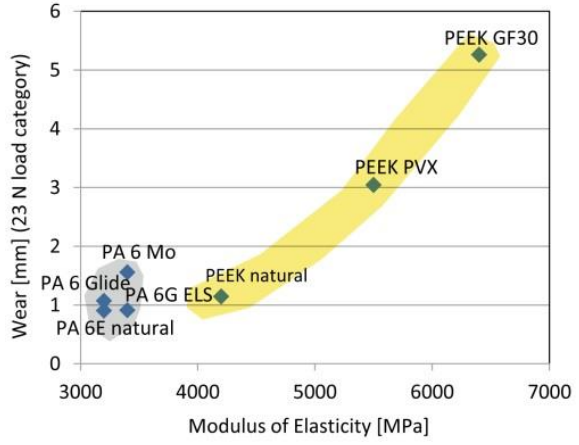

b)

Figure 9

The Shore D hardness (a) and the Modulus of Elasticity (b) of tested polymers are plotted against the measured wear (23 N load category)

From the trend lines, the following conclusions are drawn in the figures:

- We can see a correlation between the hardness and the wear in cases of polyamides (Fig. 9/a). Wear decreases with increasing Shore D hardness. However, the previous trend is not so clear in the case of PEEK because of similar hardness of PEEK composites, however the PEEK GF30 has the highest wear with a lower hardness among PEEKs.

- We can see the contrast with the previous ones, in a context between the modulus of elasticity and wear at PEEKs in Figure 9/b.

- In summary, on one hand the hardness of the polyamides have an influence on their wear, but on the other hand the PEEKs has the modulus of elasticity.

\section{Conclusions}

Based on the results of the unique experiments, the following conclusions can help and improve the further tribotesting of polymers, the selection of proper material and design. The experimental data suggests the following conclusions:

- There is a general trend from present investigations that the dynamic friction coefficient decreases with increasing normal load, and the wear is found to be 1.6-1.8 times higher at double load.

- Among the investigated polymers and composites taken from the engineering practice the PA 6Glide and PEEK natural are most suitable sliding materials, because their friction is lowest and their wear resistance is higher.

- The effect of the internal lubrication in case of cast PA 6Glide composite is different from the effect of solid PTFE lubrication in PEEK PVX. In case of PA 6 the efficiency of the lubrication gives an excellent friction coefficient and 
high wear resistance at both load categories. Opposite the PA 6Glide the addition of PTFE has a weak effect on the friction. The solid PTFE lubricant can't decrease the friction of the PEEK PVX (due to PEEK natural).

- The polyamides have a good abrasion wear resistance in connection with their increased deformation ability, but their friction coefficients do not differ significantly from the more ,rigid” PEEKs.

- The addition fillings have a different effect on the PA and PEEK composites. While these fillings have a good effect for the friction coefficients of polyamides, in case of PEEK they have an unfavourable effect at both load categories. The former are true for the abrasion wear also where the PEEK composites suffer an essential higher abrasion in comparison with polyamide composites.

- Our abrasion investigations correlate with Voss et al. [10] and Friedrich et al $[18,19]$, that short carbon fibres proved better for improving wear resistance as compared to short glass fibres, in the given circumstances.

- We observed a difference between our results and the data presented previously [17]. Other data showed differences between the friction of PEEK (high) and PA6 (low), but the wear was similar. However, in our cases the frictions were more or less similar, but we found a major difference in the wear results (exceptions the natur PA and PEEK).

- The PA 6G ELS shows individual friction properties. The Mg-catalysed polymerization of this polymer has a more efficient effect on the friction at higher load, but it does not have any individual effect on the wear between both load categories.

- The presented photos of the wear gaps are in good correlation with the wear results (homogenous and thick gaps for the PEEK composites and thin ones for the polyamides).

- The Shore D hardness of the polymers has a different effect on the wear, while it seems a correlation between them at polyamides, but does not have any at PEEKs. The modulus of elasticity has an influence of the wear in cases of PEEKs rather.

For practical use we can mention by our results, that the polyamide composites are suitable as machine elements in normal abrasive applications, as they resist again abrasion wear. However, if there are any extreme demands, for example: high mechanical properties, temperature resistance and excellent chemical resistance etc., we can use PEEK composites also, but it is important to know the character of the filling. It is clear that the glass fibre (GF) has a bad effect on the friction and the wear at abrasive surface. 
The small-scale abrasion tests with PA and PEEK polymers and composites with abrasive surface provided new information about their tribological behaviours. These results extend our tribological knowledge about polymers and show new possibilities for practical application.

\section{Acknowledgement}

The author (László Zsidai) would like to thank MTA (Hungarian Academy of Sciences) for supporting this work in the frame of the research fellowship BOLYAI (BO/00127/13/6).

Special thanks go to QuattroPlast for the delivery of material specimens.

\section{References}

[1] A. Häger, M. Davies: Advances in Composite Tribology, Elsevier, Amsterdam, 1993

[2] B. J. Briscoe: Interfacial Friction of Polymer Composites. General Fundamental Principles. In: Friedrich, K. (Ed.): Friction and Wear of Polymer Composites. Elsevier, Amsterdam (1986) pp. 25-59

[3] B. J. Briscoe and S. K, Sinha (Ed. by: G.M. Swallowe): 59-Wear, Mechanical properties and Testing Ok Polymers, Polymer Science and Technology Series, Volume 3 Springer-Science+Business Media, B. V. 1999

[4] D. Burris, W. Sawyer, A Low Friction and Ultra Low Wear Rate Peek/Ptfe Composite, Wear 261 (2006) pp. 410-418

[5] E. Rabinovicz: The Friction and Wear of Materials, John Wiley and Sons, New York, 1965

[6] F. P. Bowden, D. Tabor: The Friction and Lubrication of Solids, Clarendon Press, Oxford, 1950

[7] G. Kalácska, et al.: Müszaki műanyagok gépészeti alapjai (Mechanical Basics of Polymers), Minerva-sop Bt. Sopron, 1997

[8] G. M. Swallowe (Ed. by: G. M. Swallowe): 46-Standards for Polymer Testing, Mechanical Properties and Testing of Polymers, Polymer Science and Technology Series, Volume 3 Springer-Science+Business Media, B. V. 1999

[9] H. Uetz, J. Wiedemeyer: Tribologie der Polymere, Carl Hanser, Munich, 1985

[10] H. Voss and K. Friedrich: "On the Wear Behaviour of Short-FibreReinforced-Peek,” Wear, 116, 1, 1987. pp. 1-18

[11] I. M. Hutchings: Tribology, Friction and Wear of Engineering Materials, Arnold, London, 1992 
[12] J. B. Ratner et al.: Connection between Wear Resistance of Plastics and other Mechanical Properties. Soviet Plastics, 1964. Vol. 12 (7) 37, 145 p.

[13] J. Hanchi and N. S. Eiss Jr.: "Dry Sliding Friction and Wear of Short-FiberReinforced Poly-Etherether-Ketone (PEEK) at Elevated Temperatures," Wear, 203-204, 1997, pp. 380-386

[14] J. J. Rajesh, J. Bijwe and U. S. Tewari: "Influence of Fillers on Abrasive Wear of Short Glass Fibre Reinforced Polyamide Composites," Journal of Materials Science, 36, 2001, pp. 351-356

[15] J. J. Rajesh, J. Bijwe and U. S. Tewari: Abrasive Wear Performance of Various Polyamides, Wear, 2002. Volume 252, Issues 9-10, pp. 769-776

[16] J. R. Vail, B. A. Krick, K. R. Marchman, W. Gregory Sawyer: Polytetrafluoroethylene (PTFE) Fiber Reinforced Polyetheretherketone (PEEK) Composites, Wear, 2010. Volume 270, Issues 11-12, pp. 737-741

[17] K. Friedrich and A. K. Schlarb (Ed.: B. J. Briscoe): Tribology of Polymeric Nanocomposites. Tribology and Interface Engineering Series, 2008. No. 55

[18] K. Friedrich, J. Karger-Kocsis and Lu, Z.: "Effects of Steel Counterface Roughness and Temperature on Friction and Wear of PEEK-Composites under Dry Sliding Conditions," Wear, 148, 2, 1991, pp. 235-247

[19] K. Friedrich, Z. Lu and A. M. Häger: "Overview on Polymer Composites for Friction and Wear Application," Theoretical and Applied Fracture Mechanics, 19, 1, 1993, pp. 1-11

[20] L. C. Seabra, A. M. Baptista: Tribological Behaviour of Grade Polymers against Stainless Steel in Dry Sliding and with Sugar. Wear, 2002. Vol. 253 pp. 394-402

[21] L. Kátai, P.Gárdonyi, I. Szabó: Examination of Drive Misalignment and VBelt Temperature Conditions, International journal of science, technics and innovations for the industry, 2015, Vol. 12, pp. 56-59

[22] L. Zsidai, G. Pistai, R. Keresztes: Abrasion testing of PA 6, POM and PET composites in small scale tribology model system, The $11^{\text {th }}$ International Conference of The Carpathian Euro-Region Specialists in Industrial Systems CEurSIS 2016, 2-4 June, 2016, Baia Mare, Romania

[23] M Ando, J Sukumaran: Effect on Friction for Different Parameters in RollSlip of Polyamide-Steel Nonconformal Contacts, Tribology Transactions 2012. 55 (1) pp.109-116

[24] M. Kozma, G. Kalacska: Abrasive Wear of Polymers, in: Proceedings of the First Conference on Mechanical Engineering (Gepeszet'98), May 2829, 1998, pp. 157-161 
[25] N. Dyson, A. J. Kinloch, A. Okada: The Interlaminar Failure Behaviour of Carbon Fibre/Polyetheretherketone Composites. Composites 25, 1994. pp. 189-196

[26] P. Davies et al: Round-Robin Interlaminar Fracture Testing of CarbonFibre-reinforced Epoxy and PEEK Composites. Compos. Sci. Technol. 43, 1991, pp. 129-136

[27] Plint \& Partners Ltd.: Delivery Programme Edition. England: Newburry, Berkshire, RG20 6NB, 2001

[28] Q. Wang, Q. Xue, H. Liu, W. Shen, J. Xu,: The Effect of Particle Size of Nanometer $\mathrm{ZrO}_{2}$ on the Tribological Behaviour of PEEK, Wear 198 (1-2), 1996, pp. 216-219

[29] Q. Wang, Q. Xue, W. Shen: The Friction and Wear Properties of Nanometre $\mathrm{SiO}_{2}$ filled Polyetheretherketone, Tribology International 30 (3), 1997. pp. 193-197

[30] W. Grellmann, S. Seidler: Polymer Testing, Carl Hanser Verlag, Münich, 2007

[31] W. Hufenbach, K. Kunze, J. Bijwe: Sliding Wear Behaviour of PEEKPTFE blends, Journal of Synthetic Lubrication 20 (3), 2003. pp. 227-240

[32] W. I. Broughton: Shear. In: Hodgkinson, J.M. (Ed.): Mechanical Testing of Advanced Fibre Composites. Woodhead Publishing, Cambridge, 2000

[33] www.deerfos.com (28 .04. 2016) DEERFOS Products Information, 2008

[34] www.ensinger-online.com/modules/public/datapdf (28.4.2016)

[35] www.quattroplast.hu/files/file/B_kategoria.pdf (28.4.2016)

[36] X. Shao, Q.-J. Xue: Effect of Nanometer and Micrometer SiO(2) Particles on the Tribology Properties of Poly (phthalazine ether sulfone ketone) Composites, Materials and Mechanical Engineering (China) 28 (6), 2004, pp. 39-42

[37] Y. Yamaguchi: Tribology of Plastic Materials, Tribology Series 16, Elsevier, Amsterdam, 1990

[38] Z. Lu, K. Friedrich: High Temperature Polymer Composites for Applications as Sliding Elements, Materialwiss. Werkst. 28, 1997, pp. 116123

[39] Z. P. Lu, K. Friedrich: On Sliding Friction and Wear of Peek and its Composites, Wear 181-183 (2), 1995, pp. 624-631 